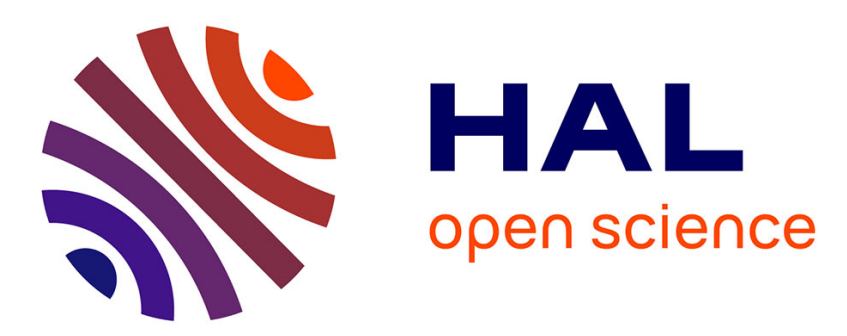

\title{
Application of boron carbide as burnable poison in sodium fast reactors
}

\author{
H. Guo, P. Sciora, T. Kooyman, L. Buiron, G. Rimpault
}

\section{To cite this version:}

H. Guo, P. Sciora, T. Kooyman, L. Buiron, G. Rimpault. Application of boron carbide as burnable poison in sodium fast reactors. Nuclear Technology, 2018, 205 (11), pp.1433-1446. 10.1080/00295450.2019.1620054 . cea-02339872

\section{HAL Id: cea-02339872 https://hal-cea.archives-ouvertes.fr/cea-02339872}

Submitted on 5 Nov 2019

HAL is a multi-disciplinary open access archive for the deposit and dissemination of scientific research documents, whether they are published or not. The documents may come from teaching and research institutions in France or abroad, or from public or private research centers.
L'archive ouverte pluridisciplinaire HAL, est destinée au dépôt et à la diffusion de documents scientifiques de niveau recherche, publiés ou non, émanant des établissements d'enseignement et de recherche français ou étrangers, des laboratoires publics ou privés. 


\title{
Application of boron carbide as burnable poison in sodium
}

\section{fast reactors}

\author{
H. Guo, P. Sciora, T. Kooyman, L. Buiron \\ Alternative Energies and Atomic Energy Commission \\ CEA, DEN, SPRC, F-13108 Saint-Paul Les Durance Cedex \\ Email: hui.guo@cea.fr
}

\begin{abstract}
:
The inherent safety performance in incidental transient is required for Generation-IV reactors. The high excess reactivity in the core to compensate for burn-up reactivity loss increases the control rod withdrawal accident in sodium fast reactor. This paper does focus on the application of absorber as burnable poisons to compensate for reactivity loss.

The coupling between boron carbide in depleted boron-10 and zirconium hydride is the most relevant burnable poison in fast neutron spectrum after evaluation of various materials. The burnable poison is implemented in independent assemblies that are fixed in the core during all the operation cycle.

Four core designs with different loading of burnable poison, from $0.79 \%$ vol to $3.97 \%$ vol of fuel, are investigated. These burnable poison designs show enough ability to compensate for reactivity loss and thus reduce the excess reactivity. The application of such design in cores with higher reactivity loss will be considered in the near future.

The burnable poison assembly is able to manage the power distribution as control rods. However, their position is fixed in the core during the cycle and thus should be determined in the design step. As including moderation materials, these designs improve slightly the reactivity feedback coefficient.
\end{abstract}

Key words: fast reactor, burnable poison, boron carbide 


\section{Introduction}

Formed in the year 2000, the Generation IV International Forum (GIF) is an intergovernmental organization that promotes the development of new technologies of nuclear reactors (GIF, 2014; Pioro, 2016). In order to be competitive with the other sources of energy, these technologies are required to meet several challenges involving sustainability, economic competitiveness, safety and resistance to proliferation of nuclear weapons. Among the candidates that fulfill all those criteria, France is particularly interested in the Sodium cooled Fast neutron Reactor (SFR) (Beck et al., 2017; Chenaud et al., 2013; Gauche and Rouault, 2011).

As for every nuclear reactor, the core at start-up exhibits excess reactivity which allows continuous operation over the length of the fuel cycle. This excess reactivity should cover burn-up reactivity loss, operation margin (loading of experimental assemblies for instance) and uncertainty margins. Due to the use of sodium as a coolant, it is not possible to use diluted boron to control the core reactivity change during irradiation. Therefore, contrary to pressurized water reactors, control rods are the only available mean of reactivity control, boron dilution in sodium being not possible. At Beginning of Equilibrium Cycle (BOEC), one part of control rods should be inserted into the core to balance this excess reactivity. The control rods are then withdrawn slowly during the cycle to compensate for burn-up reactivity loss.

A typical initiating event for unprotected transient over-power (UTOP) is a control rod withdrawal (CRW) due to a malfunction of a control rod mechanism. This event could lead to the local melting of fuel assemblies and even to the global melting of core (Varaine F. et al., 2012).

Multiples solutions can be used to prevent fuel melting in case of a total unprotected CRW accident. First, mechanical systems can be designed to prevent inadvertent control rods withdrawal. However, these systems often depend on operational logic, detectors, or mechanical motors etc. This approach has not been implemented in France so far as it relies on mechanical systems integrated with the malfunctioning device and thus complicates the safety analysis. Secondly, the maximal linear power density can be limited to obtain enough margins in terms of linear power rate during CRW transient. Thirdly, the cycle length can be adjusted to reduce the reactivity compensated by the rods for burn-up. However, these two last solutions reduce the economic performances of the reactor. A fourth solution would be to use burnable poisons (BP) as it is currently done in light water reactors (LWRs) (Goldstein and Strasser, 1983; Renier, 2002).

The burnable poisons are materials with an initial absorption capacity that should be significantly reduced under neutron irradiation. For instance, in pressurized water reactors (PWRs), boron and gadolinium are used as burnable poison to decrease the initial boric acid concentration in the primary circuit, the reactivity compensation needed, and the relative power of fresh fuel assemblies (Goldstein and Strasser, 1983; Renier, 2002).

In SFR, the burnable poisons may have a potential ability to reduce CRW accident, to extend the cycle length or to lessen the requirements on the control rods. However, they were not 
significantly investigated for SFR because of their insufficient absorption cross-section in the fast spectrum. Therefore, this paper is aimed to investigate the application of absorbers coupled with moderators as burnable poisons and try to improve their reactivity compensation capability.

The Section 2 will present the neutronic simulation tools used in this design work. The potential of different materials to achieve the burnable poison objective will be investigated in Section 3.1. The detailed designs of burnable poison assembly and their implementations in a core will be presented in Section 3.2 and 3.3. Then, the compensation ability of different designs, that is a key result for burnable poisons, will be discussed in Section 4. Finally, this paper will compare the different burnable poison designs proposed and their influence on some macroscopic parameters like the power map of a core.

\section{Methodologies}

Accurate and high performance neutronic simulation is the key for the evaluation of the innovative designs of reactivity control system. The complex geometries of these systems should be treated accurately (Blanchet and Fontaine, 2014; Tommasi et al., 2004) as the absorber is one of the most sub-critical material in the core and thus exhibits important flux gradient and self-shielding effect at a sub-assembly scale. To benefit of the last developments still ongoing, the deterministic APOLLO3 ${ }^{\circledR}$ platform (Golfier et al., 2009) is chosen for the neutronic simulation of the various designs in this work.

The calculation scheme in APOLLO ${ }^{\circledR}$ includes two steps: lattice and core calculation. The lattice calculation is based on the Method of Characteristic (TDT-MOC) (Sciannandrone et al., 2016) and is able to simulate complex geometries with exact description and compute self-shielding effects (Guo et al., 2018). The lattice calculation of multiple designs, including the conventional control rods and the innovative control assembly that mix absorber with large quantity of moderators, has been validated against TRIPOLI- ${ }^{\circledR}{ }^{\circledR}$ (Brun et al., 2015), which shows high robustness of this solver to different innovative designs (Guo et al., 2018). This lattice step is able to generate homogenized and collapsed cross-section at different burn-up that will be used in the core step.

In the core step, the 3D $S_{N}$ solver MINARET (Moller et al., 2011) is able to treat unstructured geometry. Therefore, beside the traditional homogenous description of all structures, MINARET enables to consider also a semi-heterogeneous model that permit to describe the exact geometry of the absorbers in the core geometry. Although this semi-heterogeneous model is more accurate it also impacts calculation time in significant way. The update of cross-sections according to the burn-up have been developed and leads to improve significantly the accuracy of depletion calculation because it is able to transfer the variation on self-shielding from lattice step to core step, which is particularly important for the absorber materials. With updating of cross-sections, it has been shown that the accuracy of homogenous geometry modeling is sufficient for the design work purpose (Guo et al., 2018). 
By using these newly developed and improved tools, it is feasible to achieve an accurate simulation of reactivity control system with complex configurations and thus to carry out the design work described in the following parts.

\section{Burnable poison designs}

\subsection{Candidate materials}

The challenge for the application of absorbers as burnable poison is the insufficient consumption of absorbers as their absorption cross-section generally decreases with the incident neutron energy. This section is aimed at evaluating the depletion characteristics of various absorbers and thereby selects the adequate materials for the burnable poison objectives.

In order to compensate for reactivity loss, the ideal candidate for the burnable poison should possess high variation of absorption capacity during the irradiation and limited residual negative effect at the end. The absorption ability of one material at moment $t$ can be represented by its macroscopic absorption cross-section $(\Sigma)$ that is defined as:

$$
\Sigma^{a}(\mathrm{t})=\sum_{i \in M} \sigma_{i}^{a}(t) \times c_{i}(t)
$$

Where $\mathrm{i}$ is an isotope in the material $\mathrm{M}$ with concentration $\mathrm{c}_{\mathrm{i}}$ and one-group absorption cross-section $\sigma_{i}^{a}$. The macroscopic absorption is therefore in unit $\mathrm{cm}^{-1}$.

\subsubsection{Different absorbers}

Natural boron carbide $\left(\mathrm{B}_{4} \mathrm{C}\right.$ with $\left.20 \%{ }^{10} \mathrm{~B}\right)$, depleted boron carbide $\left(\mathrm{B}_{4} \mathrm{C}\right.$ with $\left.3 \%{ }^{10} \mathrm{~B}\right)$, gadolinium oxide $\left(\mathrm{Gd}_{2} \mathrm{O}_{3}\right)$, metallic hafnium (Hf) and hafnium hydride ( $\left.\mathrm{HfH} 1_{.62}\right)$ are compared in this section because they are general absorbers used in nuclear reactors. These materials are tested in the lattice type geometry as shown in Fig. 1, in which the assembly with absorber pins is surrounded by fuel assembly that offers a fast spectrum irradiation environment. This type of geometry is used in the APOLLO ${ }^{\circledR}$ lattice calculation to generate effective cross-section library of control rods for core calculation.

The variation of macroscopic absorption cross-section in Fig. 2 is defined as $\Sigma_{\text {end }}^{\text {absorption }}(t)-\Sigma_{\text {initial }}^{\text {absorption }}$ while the relative macroscopic absorption cross-section is defined as $\sum_{\text {end }}^{\text {absorption }} / \Sigma_{\text {initial }}^{\text {absorption }}$. The effective macroscopic absorption cross-section is computed until the accumulated fluence is $10^{23} \mathrm{n} / \mathrm{cm}^{2}\left(1.8 \times 10^{15} \mathrm{n} / \mathrm{cm}^{2} / \mathrm{s}\right.$ for 579 days $)$.

Under irradiation, the boron carbide has a larger variation than other absorbers in fast spectrum. Even if the ${ }^{10} \mathrm{~B}$ concentration in the depleted boron carbide is low, its higher cross-section leads to the same depletion kinetic as the natural one. The other absorber isotopes such as hafnium and gadolinium have longer decay chain to slow down their depletion kinetic and seem to be less relevant for our objectives. Regarding the residual negative effect, the 
depleted boron carbide is more suitable than the natural boron carbide, but it seems nevertheless not sufficient to be of interest for the burnable poison objective.

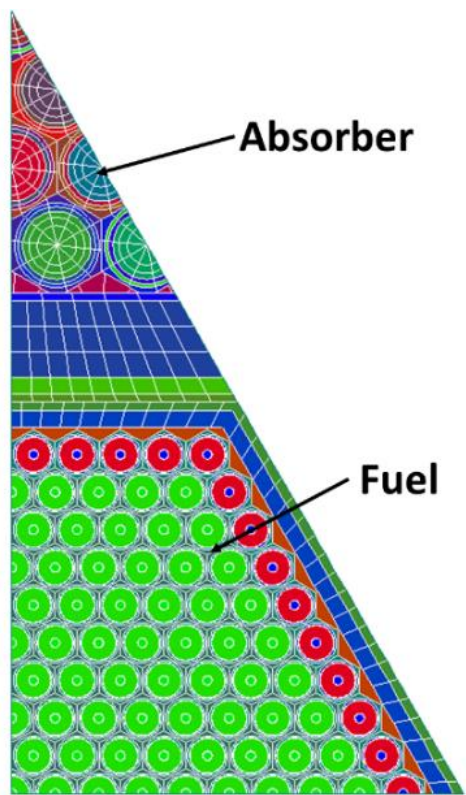

Fig. 1. The cluster geometry of a typical SFR control rods assembly surrounded by fuel assembly
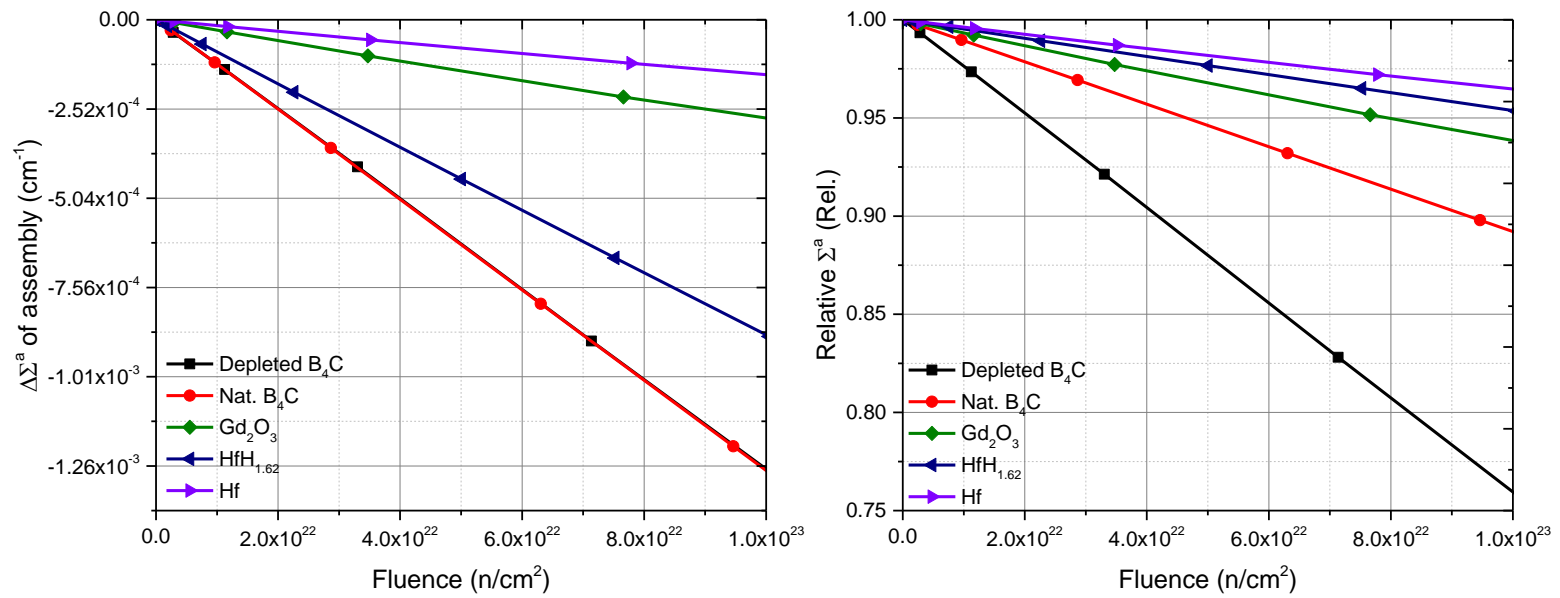

Fig. 2. The evolution of absorption macroscopic cross-sections (left) and of the relative value (right)

\subsubsection{Moderators}

According to the previous results, the hydride form increases the depletion of hafnium because the diffusing material is able to slow down the incident neutrons and thus increase the consumption rate of the absorber. The addition of moderator seems therefore to be a potential option to realize burnable poison with absorber. In this section, a simple model is considered to investigate the sensibility of the boron carbide and gadolinium oxide to the moderator. As shown in Fig. 3, two layers of absorber pins are replaced by the moderator pins. Zirconium hydride 
$\left(\mathrm{ZrH}_{1.72}\right)$ is considered as moderator in this paper because of its high moderation capability.

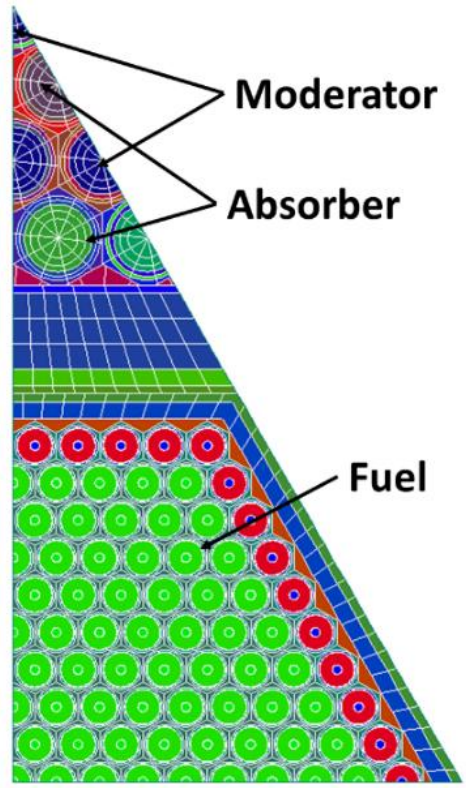

Fig. 3. Cluster geometry of the control rods with moderator assembly surrounded by fuel assembly

As shown in Table 1, the addition of moderator increases significantly the variation of the macroscopic cross-section and reduces their residual negative effect. With absorption resonance, the gadolinium is more sensitive to the moderation, but it still remains not competitive with the boron carbide. The depleted boron carbide seems to be more suitable than the natural one in this case. However, considering the behavior of natural and depleted boron carbide, it appears that an optimal ${ }^{10} \mathrm{~B}$ concentration can be found depending on the reactivity compensation objective. This will be investigated in Section 3.2.

Table 1. Variation of macroscopic absorption cross-section in assembly (Fluence $=10^{23} \mathbf{n} / \mathrm{cm}^{2}$ )

\begin{tabular}{cccc}
\hline & $\Sigma_{\mathrm{i}}\left(\mathrm{cm}^{-1}\right)$ & $\Delta \Sigma\left(\mathrm{cm}^{-1}\right)$ & $\Sigma_{\mathrm{f}} / \Sigma_{\mathrm{i}}($ Rel. $)$ \\
\hline $\mathrm{B}_{4} \mathrm{C} 3 \%{ }^{10} \mathrm{~B}$ & $5.27 \mathrm{E}-03$ & $-1.35 \mathrm{E}-03$ & 0.76 \\
$\mathrm{~B}_{4} \mathrm{C} 3 \%{ }^{10} \mathrm{~B}+\mathrm{ZrH}_{1.72}$ & $8.49 \mathrm{E}-03$ & $-4.23 \mathrm{E}-03$ & 0.50 \\
$\mathrm{~B}_{4} \mathrm{C} 20 \%{ }^{10} \mathrm{~B}$ & $1.18 \mathrm{E}-02$ & $-1.21 \mathrm{E}-03$ & 0.90 \\
$\mathrm{~B}_{4} \mathrm{C} 20 \%{ }^{10} \mathrm{~B}+\mathrm{ZrH}_{1.72}$ & $1.38 \mathrm{E}-02$ & $-2.13 \mathrm{E}-03$ & 0.85 \\
$\mathrm{Gd}_{2} \mathrm{O}_{3}$ & $4.53 \mathrm{E}-03$ & $-3.16 \mathrm{E}-04$ & 0.93 \\
$\mathrm{Gd}_{2} \mathrm{O}_{3}+\mathrm{ZrH}_{1.72}$ & $8.40 \mathrm{E}-03$ & $-9.73 \mathrm{E}-04$ & 0.88 \\
\hline
\end{tabular}

This section investigated the depletion characteristics of different absorbers, with and without moderators in fast spectrum cores. The boron carbide appears as the best candidate for our burnable poison objective thanks to its compromise between large initial macroscopic absorption cross-section and small residual effects. The application of moderator is necessary to 
optimize the burnable poison design in fast spectrum.

\subsection{Burnable poison assembly}

In this work, the boron carbide and zirconium hydride are packaged in independent burnable poison assembly. This independent design is aimed at reducing the impact on the fuel handling and recycling by separating the burnable poisons from the fuel. This section will present the design of burnable poison assemblies and their location in the core.

The radial layout of poisons design used in this paper is shown in Fig. 4. In the center of this assembly, a layer of boron carbide is mixed with a layer of moderator to maximize the moderation effects. The absorbers and moderators are surrounded by the steel to reduce their influence on the neighboring fuel assemblies. By comparison with traditional absorber pins in SFR control rods, the size of absorber pin is adopted to arrange more flexibly the absorber and moderators. Moreover, the small size pin with central hole is able to reduce the centerline temperature in absorber because the moderator increases significantly the absorption cross-sections of ${ }^{10} \mathrm{~B}$ and thus its power density (See Section 4.2.1). In the near future, the fabrication feasibility and the gap filler will be considered to optimize current design.

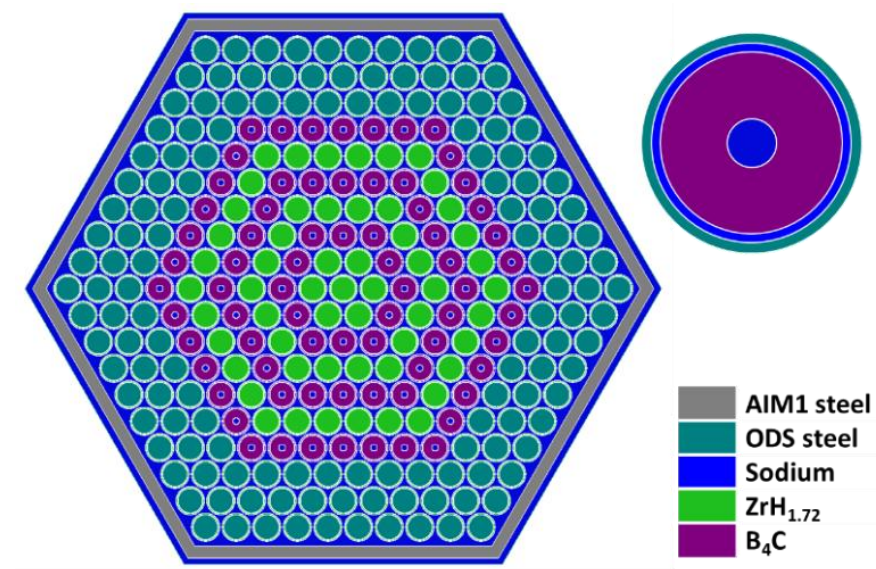

Fig. 4. Radial layout of burnable poison assembly (left) and its absorber pins (right upper)

The one-group effective absorption cross-section of boron carbide in Fig. 4 increases significantly with the decrease of the ${ }^{10} \mathrm{~B}$ concentration (See Fig. 5).

The relationship between the variations of macroscopic absorption cross-section in all the burnable poison assemblies and the initial ${ }^{10} \mathrm{~B}$ concentration is shown in Fig. 6 . The ratio between the end and the initial macroscopic cross-section is plotted with the right ordinate axis. The calculations are done by supposing that the accumulated fluence is $6.3 \times 10^{22} \mathrm{n} / \mathrm{cm}^{2}\left(1.8 \times 10^{15}\right.$ $\mathrm{n} / \mathrm{cm}^{2} / \mathrm{s}$ for 410 days). For both large variations and small residual considerations, the optimal ${ }^{10} \mathrm{~B}$ concentration is about one-tenth of natural boron carbide. For higher concentrations, the absorption cross-section is too small to achieve enough consumption and thus there is an important residual absorption at the end. For lower concentration, the absorber isotope is 
over-consumed which means that the macroscopic cross-section is reduced to zero before the end of irradiation.

This optimal concentration depends on the accumulated fluence and on the position in the core. The simulation of such assembly is in fact very sensitive to the calculation scheme. The cross-sections vary with the consumption and hence the depletion kinetic varies with the time. In summary, the variation of cross-section with time and fine time mesh should be considered for either stochastic or deterministic method.

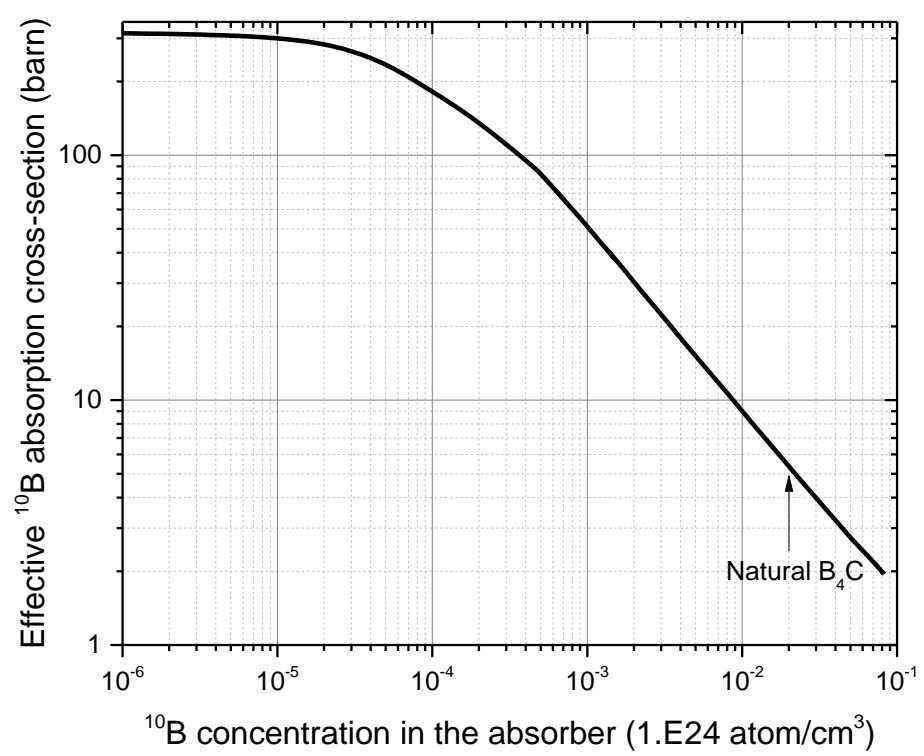

Fig. 5. Evolution of ${ }^{10} \mathrm{~B}$ absorption cross-section with ${ }^{10} \mathrm{~B}$ concentration

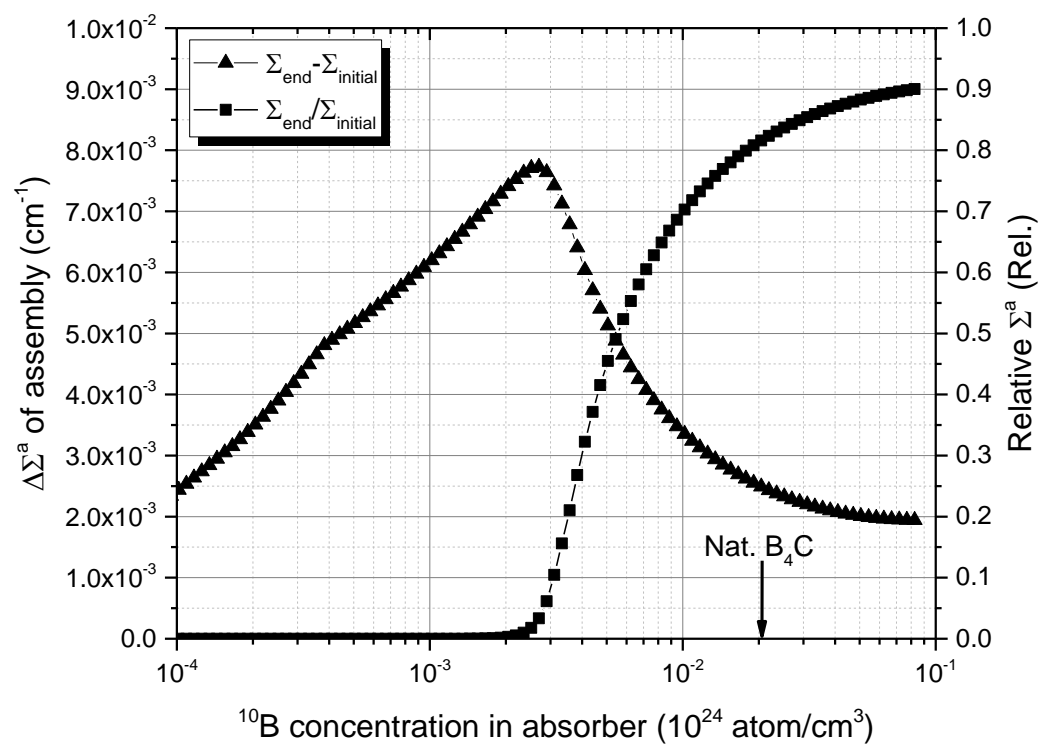

Fig. 6. Evolution of variation of macroscopic absorption cross-section with ${ }^{10} \mathrm{~B}$ concentration 
The axial layouts of the burnable poison assemblies used in the following are described in Fig. 7 by comparison with the fuel assembly. The burnable poison pins are in the same axial position as the fuel in order to benefit from the maximal flux level. The four different burnable poison assemblies, from BP S/A 1 to BP S/A 4, use the same radial design presented in Fig. 4, but they are made of four different heights to adjust their quantity.

In the following, a slightly lower concentration than optimal value is used to avoid the uncertainty of the fluence in order to ensure that the residual effect on reactivity remains zero. The boron-10 concentration used in each burnable poison zone is presented in Table 2. As a reference value, the ${ }^{10} \mathrm{~B}$ concentration in natural boron carbide is $2.036 \times 10^{22}$ at. $/ \mathrm{cm}^{3}$.

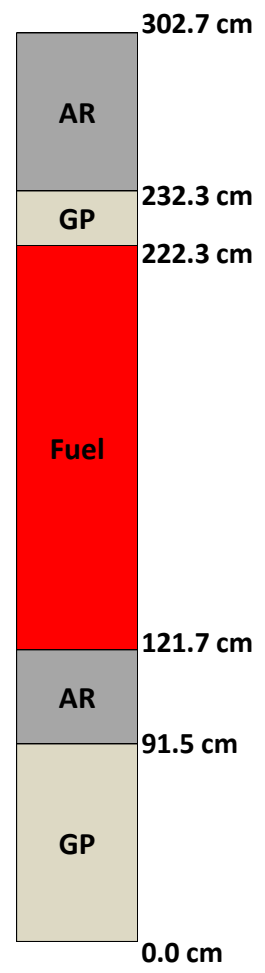

Fuel S/A

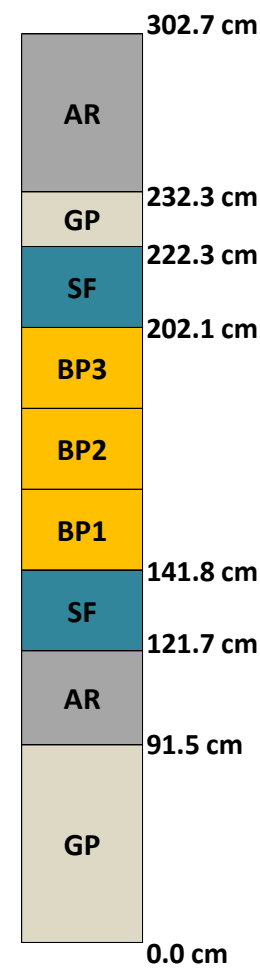

BP S/A - 1

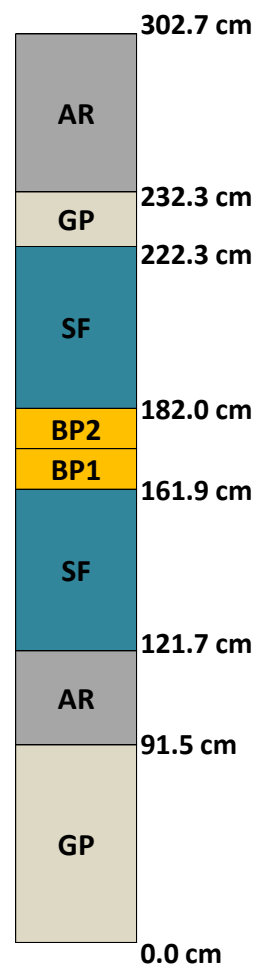

BP S/A - 2

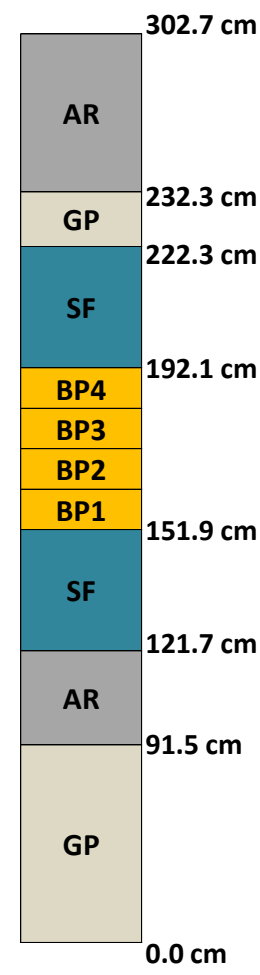

BP S/A - 3

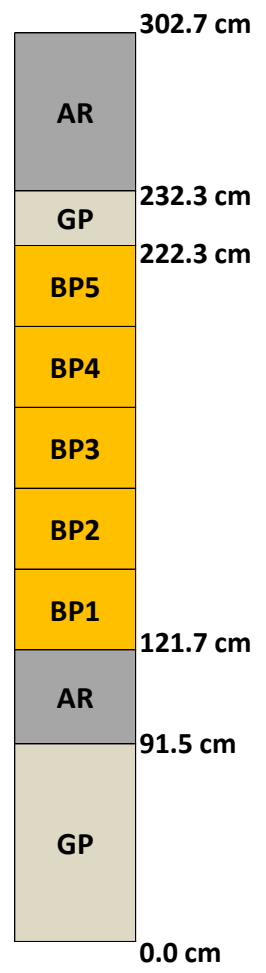

BP S/A - 4

GP: Gas plenum; AR: Axial reflector; SF: Sodium follower

Fig. 7. Axial layout of reference fuel assembly and burnable poison assemblies

Table 2. Boron-10 concentration used in burnable poison assembly in Fig. $7\left(\times 10^{24} \mathrm{at} . / \mathrm{cm} 3\right)$

\begin{tabular}{lcccc}
\hline & BP S/A - 1 & BP S/A - 2 & BP S/A - 3 & BP S/A - 4 \\
\hline BP1 & $2.19 \mathrm{E}-03$ & $2.19 \mathrm{E}-03$ & $2.19 \mathrm{E}-03$ & $7.50 \mathrm{E}-04$ \\
BP2 & $2.35 \mathrm{E}-03$ & $2.19 \mathrm{E}-03$ & $2.19 \mathrm{E}-03$ & $1.63 \mathrm{E}-03$ \\
BP3 & $2.19 \mathrm{E}-03$ & & $2.19 \mathrm{E}-03$ & $1.63 \mathrm{E}-03$ \\
BP4 & & & $2.19 \mathrm{E}-03$ & $1.63 \mathrm{E}-03$ \\
BP5 & & & & $7.50 \mathrm{E}-04$ \\
\hline
\end{tabular}




\subsection{Cores with burnable poison}

SFR-V2B core design (Mignot et al., 2008; Sciora et al., 2009) is chosen in this work because it is a representative SFR with MOX fuel. This core has been designed to achieve objectives defined for Generation-IV reactors. This concept is based on a bundle of tightly packed and large-diameter fuel pins designed to increase the fuel fraction in the core while reducing the sodium fraction. By comparison with other SFR, its reduced reactivity swing is the relevant characteristic to start the application of burnable poisons in SFRs.

As shown in Fig. 8, the SFR-V2B reference core has 267 inner core assemblies and 186 outer core assemblies. The core has two independent control rod systems. The first system is designed for the reactor operation (burn-up reactivity compensation, power management etc.) and also for shutdowns needs. This system is named CSD (Control Shutdown System) and is spatially distributed over two rings: the first one CSD1 has 6 assemblies that are located in the inner core and the second one CSD2 has 18 assemblies that are located at the interface between inner and outer core. The second system has 12 assemblies inside the inner core and is named DSD (Diverse Shutdown System) that is dedicated to the emergency shutdown. CSD and DSD are redundant, independent, and diverse to ensure a safe reactor shutdown at any time needed.

The CSD2 is inserted $25 \mathrm{~cm}$ into the core at BOEC and withdrawn slowly with time to compensate for the burn-up reactivity loss. The position of CSD2 is an optimal result from several design iterations because it is not only used to compensate for reactivity loss but also to optimize the power distribution.

The objective of burnable poison designs is to reduce the reactivity loss of the SFR-V2B core to zero. Moreover, the burnable poison assemblies are placed in dedicated positions in the core. Their impact on the power distribution will be assessed in the next paragraphs. The CSD2 in SFR-V2B are also replaced by burnable poison assemblies. Two radial layouts of core with burnable poison are considered (See Fig. 8): one presents 6 CSD2 assemblies with burnable poison assemblies and the other one replaces all CSD2 with burnable poison assemblies.
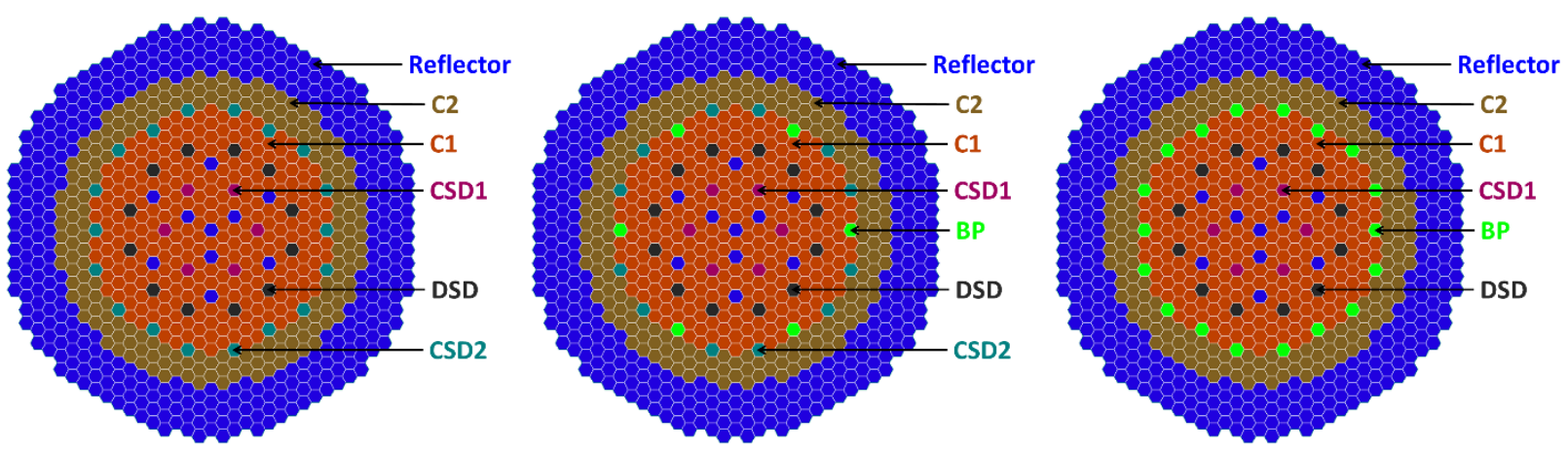

Fig. 8. Radial layout of reference core: Core-0 (left); core with 6 burnable poison assemblies: Core-1 (center); core with 18 burnable poison assemblies: Core-2 (right)

After one irradiation cycle, 410 EFPD for the SFR-V2B, about $1 / 5^{\text {th }}$ fuel are renewed at the 
End of Equilibrium Cycle (EOC). Therefore, the fuel assemblies stay in the core 2050 EFPD and are discharged with an average burn-up about $100 \mathrm{GW} \cdot \mathrm{D} / \mathrm{t}$. On the other hand, the burnable poison assemblies are all replaced at each cycle.

Finally, four burnable poison designs in Table 3 are presented in this paper. The volume fraction of burnable poison is the ratio between burnable poison volume and fuel volume. The $\mathrm{B} 4 \mathrm{CBP} 1$ and B4CBP2 have the same volume of burnable poison but with different assembly number. The difference between these two configurations will be discussed in the following (See Section 4.2.2 and 0). The B4CBP3 and B4CBP4 increase the volume of burnable poison to test the potential of such design. The average plutonium content is adjusted to achieve $750 \mathrm{pcm}$ reactivity at EOEC as for the reference design, while keeping the fixed ratio between inner and outer core. It can be seen that the addition of burnable poisons has a limited impact on the required plutonium content in order to keep the same cycle length.

Table 3. Burnable poison design with boron carbide in SFR-V2B

\begin{tabular}{ccccccc}
\hline Design & $\begin{array}{c}\text { Core } \\
\text { See Fig. 8 }\end{array}$ & $\begin{array}{c}\text { Av. plutonium } \\
\text { content }(\% \text { wt) }\end{array}$ & $\begin{array}{c}\text { BP S/A } \\
\text { See Fig. 7 }\end{array}$ & $\begin{array}{c}\text { BP S/A } \\
\text { number }\end{array}$ & $\begin{array}{c}\text { BP height } \\
(\mathrm{cm})\end{array}$ & $\begin{array}{c}\text { BP volume } \\
\text { fraction (\%) }\end{array}$ \\
\hline Reference & Core-0 & 15.56 & -- & & & 0.00 \\
B4CBP1 & Core-1 & 15.60 & S/A-1 & 6 & 60 & 0.79 \\
B4CBP2 & Core-2 & 15.60 & S/A-2 & 18 & 20 & 0.79 \\
B4CBP3 & Core-2 & 15.69 & S/A-3 & 18 & 40 & 1.59 \\
B4CBP4 & Core-2 & 15.88 & S/A-4 & 18 & 100 & 3.97 \\
\hline
\end{tabular}

This section has presented the design of burnable poison assembly and their location in the core. The design is optimized by adjusting ${ }^{10} \mathrm{~B}$ concentration to get the largest variation on the absorption ability. Finally, four cores with burnable poison have been constructed based on the SFR-V2B core and they will be studied in the following part.

\section{Compensation ability and influence of burnable poisons}

\subsection{Reactivity compensation ability}

The reactivity variation of these designs is plotted in Fig. 9. The excess reactivity in the reference SFR-V2B core decreases from $1177 \mathrm{pcm}$ at BOEC to $750 \mathrm{pcm}$ at EOEC. The control rods are inserted to balance the excess reactivity but with risk of a CRW accident especially at BOEC. The $750 \mathrm{pcm}$ at EOEC is the minimal excess reactivity considered for operation and uncertainty margin. Therefore, the objective of burnable poison is to reduce the 427 pcm burn-up reactivity loss while keeping the core critical during the entire cycle.

The initial core reactivity of the design with burnable poison is lower than the reference one. The $\mathrm{B} 4 \mathrm{CBP} 1$ and the $\mathrm{B} 4 \mathrm{CBP} 2$ reduce the core excess reactivity at BOEC respectively by 347 pcm and 419 pcm. Moreover, they both keep enough margins for operation and uncertainty 
during all the cycle. The B4CBP1 and the B4CBP2 realize the objective of burnable poison. However, the core reactivity varies not linearly with time because the depletion kinetic of boron carbide increases first and then decreases. For instance, the core reactivity in B4CBP2 varies between $718 \mathrm{pcm}$ and $777 \mathrm{pcm}$ during all the cycle, which requires the regulation of control rods to balance this reactivity.

The B4CBP3 and the B4CBP4 are overqualified for the SFR-V2B core. Their reactivity compensation ability is respectively $729 \mathrm{pcm}$ and $1022 \mathrm{pcm}$ that is higher than the burn-up reactivity loss in SFR-V2B. Although these two designs prove the capability of burnable poisons with boron carbide, there are not suitable in the present design since their initial reactivity are lower than the EOEC one. Their applications in cores with higher reactivity loss are ongoing.

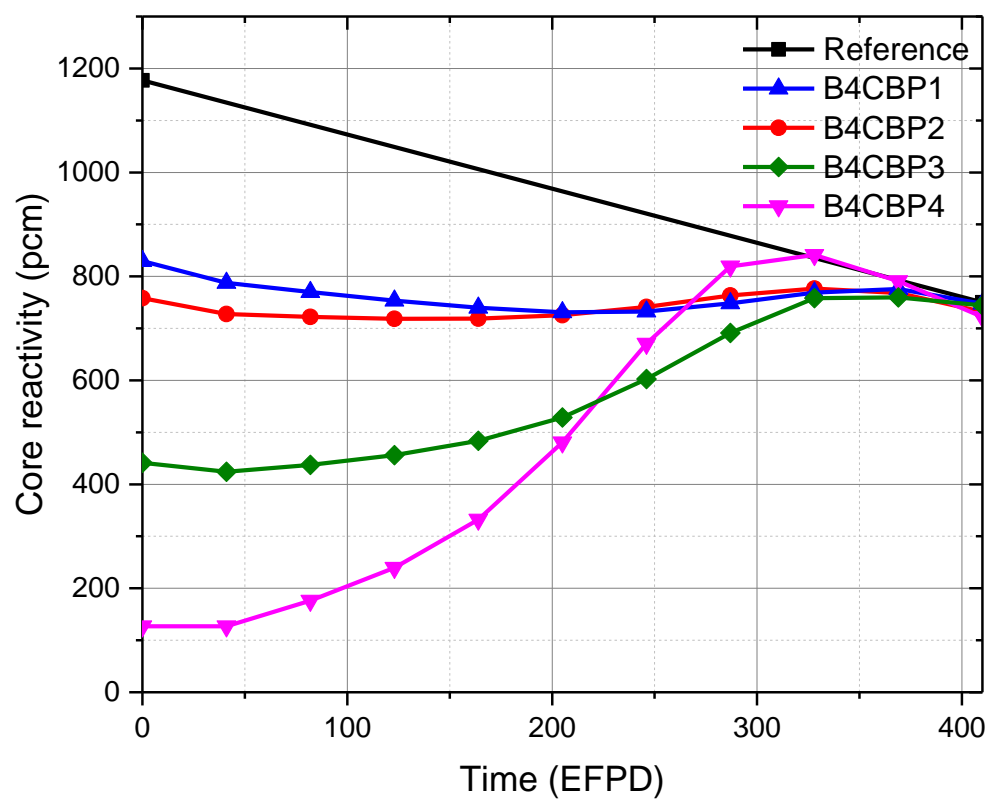

Fig. 9. Core reactivity variation at equilibrium cycle

\subsection{Influence of burnable poisons implementation}

The burnable poison assemblies with absorber and moderator impact the core characteristics. This section is aimed at studying their impact from assembly to core level. The distribution of power density in burnable poison assemblies and in the core will be presented first. Then, the impact on the neighboring fuel assemblies will be discussed. This section will be ended by the core "safety" performance.

\subsubsection{Power distribution in burnable poison assembly}

The distributions of the linear heat rating in the B4CBP2 burnable assembly at BOEC and EOEC are presented Fig. 10, which is calculated by APOLLO3 ${ }^{\circledR}$ TDT-MOC solver without considering the gamma heating. At BOEC, the linear heat rating varies between 28 and $52 \mathrm{~W} / \mathrm{cm}$. As the ${ }^{10} \mathrm{~B}$ is almost fully consumed at EOEC, the associated linear heat rating is very low. Even 
with conservative estimation, the maximal temperature in these absorber pins (850 $\mathrm{K}$ in $1-\mathrm{D}$ dimensional calculation) exhibits large margin to the melting temperature. However, the characteristics of boron carbide under irradiation must be investigated and be accounted in future optimizations.

At BOEC, the power density increases from the outer region to the inner region because of the moderation effects of the multiple zirconium hydride layers. This distribution is nevertheless reversed at EOEC because the inner region has been further depleted. For the designs used in this paper, all absorber pins have the same ${ }^{10} \mathrm{~B}$ concentration. In near future, this design could be optimized by considering a higher initial ${ }^{10} \mathrm{~B}$ concentration in the inner region to benefit from the moderated neutrons and hence to increase the consumption of absorber materials.
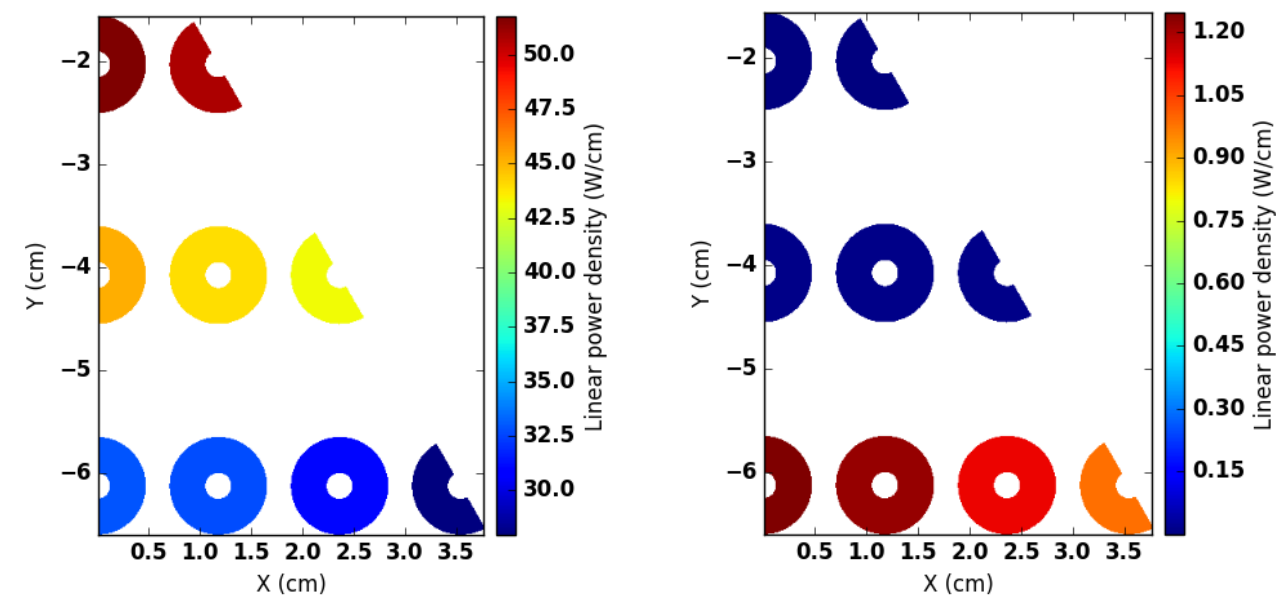

Fig. 10. Linear heat rating in the $1 / 12^{\text {th }}$ burnable poison assembly at BOEC (left) and EOEC (right)

\subsubsection{Core power distribution}

The impacts of the B4CBP1 and the B4CBP2 on the core power distribution are presented in Fig. 11 and Fig. 12. The discrepancy on these two figures is defined as $\frac{v^{B 4 C B P}-v^{\text {reference }}}{v^{\text {reference }}} \times$ 100, where the $v$ is the average linear heat rating in each assembly. The maximal value in the core is summarized in Table 4.

For B4CBP1 configuration, one third of the CSD2 assemblies are replaced by burnable poison assemblies. The remaining CSD2 are kept at the top of fissile zone because the burnable poison is able to compensate for almost all the reactivity loss. At BOEC, the linear heat rating is increased for the fuel assemblies surrounding the CSD2 in the B4CBP1 design while the assemblies surrounding the burnable poison assemblies show a reduction. This impact on the power density is less significant at EOEC because the burnable poisons are consumed and the CSD2 are also withdrawn to the top of the fissile zone in the reference core. Consequently, the burnable poison assemblies in B4CBP1 increase the power pic (in 3D computation) by $7.7 \%$ at BOEC and by $2.7 \%$ at EOEC (See Table 4). 

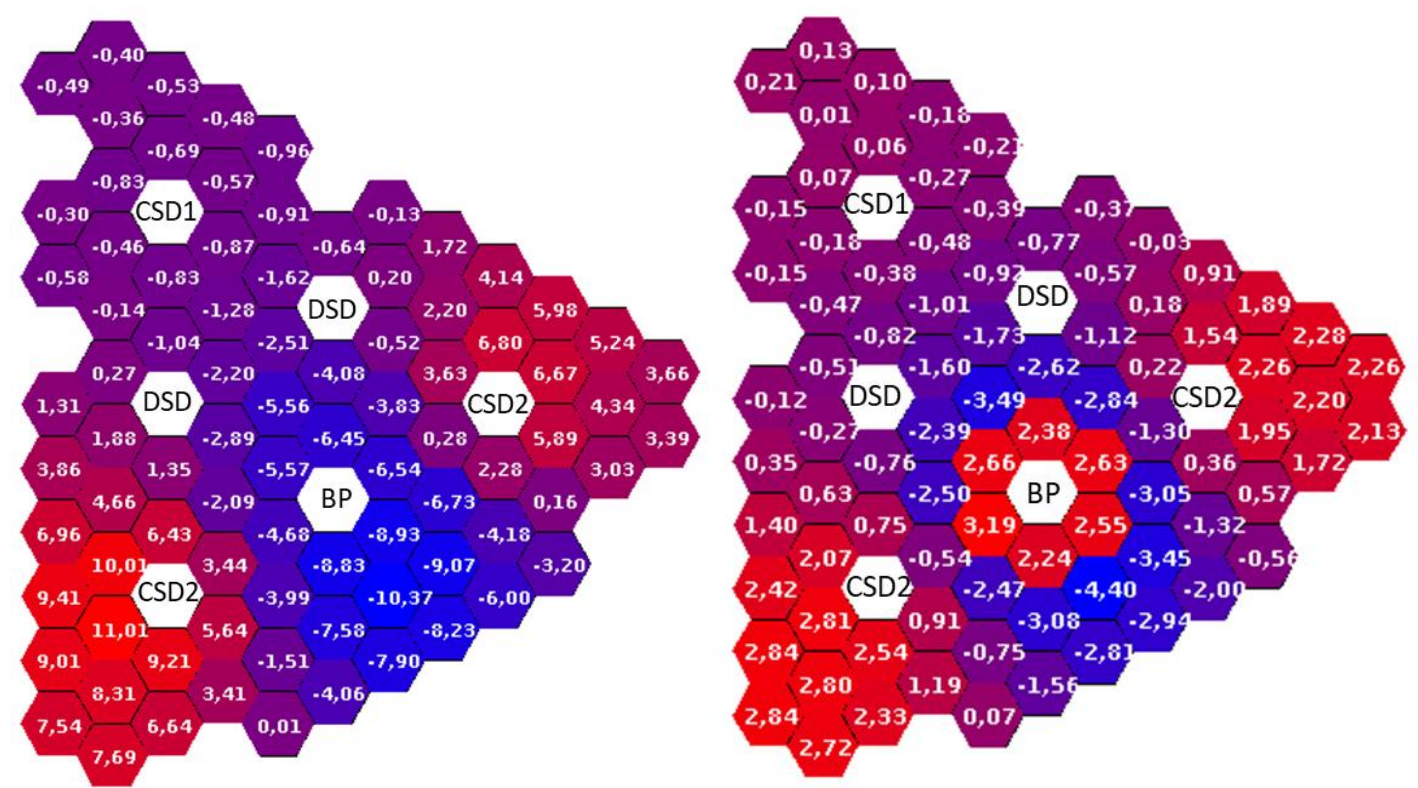

Fig. 11. Discrepancy on power distribution between B4CBP1 core and reference core at BOEC (left) and EOEC (right) (Units: \%)

The B4CBP2 replace all CSD2 with burnable poison assemblies. Therefore, its influence is less significant. The B4CBP2 decreases the power pic by $1.4 \%$ at BOEC but increases by $2.7 \%$ at EOEC. The impact of $\mathrm{B} 4 \mathrm{CBP} 3$ and $\mathrm{B} 4 \mathrm{CBP} 4$ is not presented here because they are overqualified for SFR-V2B core.
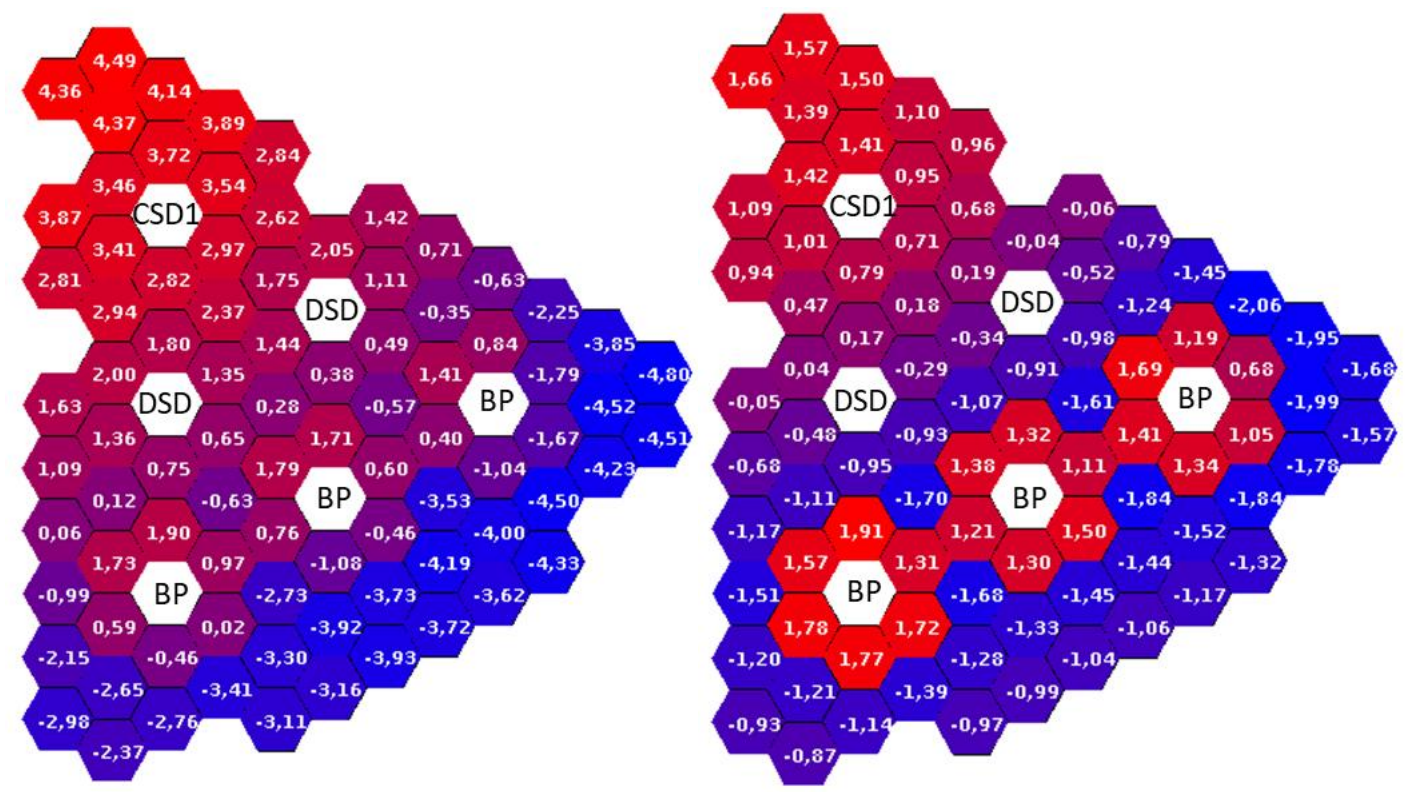

Fig. 12. Discrepancy on power distribution between B4CBP2 core and reference core at BOEC (left) and EOEC (right) (Units: \%) 
The burnable poison is able to impact the power distribution like control rods because its absorber depletion process has an effect similar to the withdrawal process of control rods. This investigation proves that the burnable poison assembly is able not only to compensate for the reactivity loss but also to keep a flattened power distribution like control rods. However, the burnable poisons are fixed during the cycle and thus their positions should be well designed.

Table 4. Maximal linear heat rating different cores $(\mathrm{W} / \mathrm{cm})$

\begin{tabular}{ccc}
\hline & BOEC & EOEC \\
\hline Ref & 445 & 419 \\
B4CBP1 & 479 & 430 \\
B4CBP2 & 438 & 450 \\
\hline
\end{tabular}

\subsubsection{Feedback coefficient}

The feedback coefficients, i.e. sodium void worth and Doppler constant, are compared between different designs in Table 5. The neutron energy spectrum shifted by moderators decreases slightly the reactivity inserted by a loss of sodium. The Doppler feedback is more negative due to the local moderation of the neutron spectrum. The burnable poisons with boron carbide are able to improve the safety coefficient but future transient analysis is required.

Table 5. Core feedback coefficient at the end of equilibrium cycle (Unit: pcm)

\begin{tabular}{ccc}
\hline Design & Sodium void worth & Doppler constant \\
\hline Reference & 2123 & -916 \\
B4CBP1 & 2118 & -938 \\
B4CBP2 & 2112 & -955 \\
B4CBP3 & 2104 & -969 \\
B4CBP4 & 2087 & -976 \\
\hline
\end{tabular}

\subsubsection{Influence on reactivity control}

The reactivity control system should satisfy multiple missions including:

1. Core shutdown: they must contain enough negative reactivity to ensure safe core shutdown regardless of the core operating situation and keep enough margin for the fuel handing error.

2. Reactivity management: they must have enough worth to compensate for the core burn-up reactivity loss.

3. Power distribution fine tuning: control rods can be used to locally modify the power distribution in the core.

4. Power regulation: the control rods can be used to adjust the power level in the core depending on the load on the turbine.

From the previous discussions, it can be concluded that the burnable poison with absorber is 
able to compensate for reactivity loss and partially control the power distribution like the operation control rods. However, the burnable poisons are not movable during the cycle and thus the fine regulation control rods are still needed. As the burnable poison share the reactivity management mission, such regulation control rod doesn't need important reactivity worth and thereby can be realized by some less efficient but longer-lived material such as gadolinium and hafnium investigated in Section 3.1.1.

In our design, the burnable poison assemblies occupy the positions CSD2 that are used to the reactivity management, power management and core shutdown. The shutdown mission and the local power regulation objective of CSD2 can't be taken over by the burnable poison and thus the "Core 2" (See Fig. 8) will not have probably enough ability to shut down the core with enough margins. The implementation of burnable poison assemblies and shutdown control rods should be considered in future optimizations.

\section{Conclusions}

This paper concerns the application of absorber, coupling with moderators, as burnable poison in fast spectrum reactors. Depleted boron carbide with the use moderator is found as the best candidate among different materials tested. The designs of burnable poisons and their implementation are presented, followed by the discussion of their compensation ability and influence on the core performances.

A fine tuned burnable poison solution with boron carbide is able to compensate for the reactivity loss from $400 \mathrm{pcm}$ to $1000 \mathrm{pcm}$. Only $0.79 \%$ of the fuel volume fraction is sufficient to compensate for reactivity loss in SFR-V2B core using burnable poison. Moreover, the burnable poison assembly shows a potential to manage power distribution similar to the one of control rods. This solution is versatile enough to be adapted to large core configurations as a substitute to control rods devices in some interesting ways.

This paper also exhibits the positive effect of such solution on the core feedback coefficient. However, the transient performance, especially the unexpected control rod withdrawal accident must be characterized in the next step work in order to fully assess the viability of such design.

This work is based on a large oxide sodium fast reactor. In the near future, the application of burnable poisons with minor actinides or boron carbide will be investigated in a small modular fast reactor with a more important reactivity loss. 


\section{References}

Beck, T., Blanc, V., Escleine, J.-M., Haubensack, D., Pelletier, M., Phelip, M., Perrin, B., Venard, C., 2017. Conceptual design of ASTRID fuel sub-assemblies. Nucl. Eng. Des. 315, 51-60. https://doi.org/10.1016/j.nucengdes.2017.02.027

Blanchet, D., Fontaine, B., 2014. Control Rod Depletion in Sodium-Cooled Fast Reactor: Models and Impact on Reactivity Control. Nucl. Sci. Eng. 177, 260-274.

https://doi.org/10.13182/NSE13-59

Brun, E., Damian, F., Diop, C.M., Dumonteil, E., Hugot, F.X., Jouanne, C., Lee, Y.K., Malvagi, F., Mazzolo, A., Petit, O., Trama, J.C., Visonneau, T., Zoia, A., 2015. TRIPOLI-4®, CEA, EDF and AREVA reference Monte Carlo code. Ann. Nucl. Energy 82, 151-160. https://doi.org/10.1016/j.anucene.2014.07.053

Chenaud, M., Devictor, N., Mignot, G., Varaine, F., VéNard, C., Martin, L., Phelip, M., Lorenzo, D., Serre, F., Bertrand, F., Alpy, N., Le Flem, M., Gavoille, P., Lavastre, R., Richard, P., Verrier, D., Schmitt, D., 2013. Status of the ASTRID core at the end of the pre-conceptual design phase 1. Nucl. Eng. Technol. 45, 721-730.

Gauche, F., Rouault, J., 2011. French SFR R\&D Program and Design Activities for SFR Prototype ASTRID. Energy Procedia 7, 314-316. https://doi.org/10.1016/j.egypro.2011.06.040

GIF, 2014. Technology Roadmap Update for Generation IV Nuclear Energy Systems. GIF.

Goldstein, L., Strasser, A.A., 1983. A Comparison of Gadolinia and Boron for Burnable Poison Applications in Pressurized Water Reactors. Nucl. Technol. 60, 352-361. https://doi.org/10.13182/NT83-A33122

Golfier, H., Lenain, R., Calvin, C., Lautard, J.J., Baudron, A.M., Fougeras, P., Magat, P., Martinolli, E., Dutheillet, Y., 2009. APOLLO3®: A common project of CEA, AREVA and EDF for the development of a new deterministic multi-purpose code for core physics analysis.

Presented at the International Conference on Mathematics, Computational Methods and Reactor Physics (M\&C 2009), Saratoga Springs, New York, USA.

Guo, H., Martin, G., Buiron, L., 2018. Improvement of sodium fast reactor control rods calculations with APOLLO3. Presented at the ICAPP 2018, Charlotte, North Carolina, USA.

MARSAULT-Marie-Sophie, F.V.-P., CONTI, C.-B.B., FONTAINE, P.S.-C.V., MARTIN, N.D.-L., VERRIER, A.-C.S., 2012. Pre-conceptual design study of ASTRID core. Presented at the ICAPP12, Chicago, USA.

Mignot, G., Klein, J.C., Chenaud, M.S., Thevenot, C., Ravenet, A., Valentin, M.P.B., Masoni, P., Dubuisson, P., Delafontaine, S., Nicolas, L., Verrier, D., Scholer, A.C., Ruah, D., Garat, V., Lecarpentier, D., Tetart, P., Maliverney, B., Massara, S., 2008. Studies on french SFR advanced core designs. Presented at the ICAPP, Anaheim, CA, USA.

Moller, J.Y., Lautard, J.J., Schneider, D., 2011. Minaret, a deterministic neutron transport solver for nuclear core calculations. Presented at the M\&C 2011, Rio de Janeiro, RJ, Brazil.

Pioro, I.L., 2016. 2 - Introduction: Generation IV International Forum, in: Handbook of Generation IV Nuclear Reactors, Woodhead Publishing Series in Energy. Woodhead Publishing, 
pp. 37-54. https://doi.org/10.1016/B978-0-08-100149-3.00002-1

Renier, J.A., 2002. Development of Improved Burnable Poisons for Commercial Nuclear Power Reactors (No. ORNL/TM--2001/238). ORNL Oak Ridge National Laboratory (United States). Funding organisation: US Department of Energy (United States).

Sciannandrone, D., Santandrea, S., Sanchez, R., 2016. Optimized tracking strategies for step MOC calculations in extruded 3D axial geometries. Ann. Nucl. Energy 87, 49-60.

https://doi.org/10.1016/j.anucene.2015.05.014

Sciora, P., Buiron, L., Rimpault, G., Varaine, F., 2009. A break even oxide fuel core for an innovative SFR: CEA neutronic studies.

Tommasi, J., Czernecki, S., Rimpault, G., Varaine, F., 2004. Analysis of Superphenix and Phenix neutron physics experiments with the ERANOS code and data system. Decommissioning Exp. Fast React. 231. 